(and sometimes personal) futures. Elizabeth Windsor reminisces about her father's relation to the School; Robert B. Downs summarizes the School's third quarter-century; Alice Lohrer remembers the hazards and rewards of early extension teaching; and twenty-four others recall different aspects of the School, its faculty, and graduates. The publication was planned and edited by Barbara Slanker, SecretaryTreasurer of the Library School Association. Mrs. Slanker was assisted by Mrs. Barbara Wallen of the Library School's Publications Office. The paperbound volume, which contains several pages of pictures, can be obtained for \$2.00 from: Graduate School of Library Science, Publications Office, 435 Library, University of Illinois, Urbana, Illinois 61801.

- The 4th edition of the University of Rochester's Science Libraries Consolidated Shorttitle Catalog of Books is now available at $\$ 8.00 /$ copy. The libraries covered are: Chemistry, Engineering, Geological Sciences, Life Sciences, and Physics-Math-Optics-Astronomy. Address all inquiries to Leon Creek, Science Libraries Office, Rush Rhees Library, University of Rochester, Rochester, New York 14627. Checks should be made out to the University of Rochester Library.

- The latest part of the English Full Edition of the Universal Decimal Classification to be published by BSI is BS $1000(656 / 656.7)$ "Transport services, traffic organization and control." Versions of the UDC are now published in many different languages, and the British Standards Institution (BSI) publishes an abridged and a full edition of the English version as parts of BS 1000. This new section forms part of the full edition and comprises a systematic schedule with an alphabetical subject index for the classification of matter pertaining to the organization, management and operation of land, water and air transport services. It provides for such aspects as routes and timetables, traffic studies, tariffs, ticket issue and control, disruptions, liability of operator, traffic control and vehicle operation, types of service and administration, accidents and damage, and various documents, e.g., certificates and licenses. Copies of BS $1000(656 / 656.7)$ may be obtained from the BSI Sales Office at 101/113 Pentonville Road, London N.1. Price 20 s each (postage ls extra to non-subscribers).

- The United States of America Standards Institute has announced publication of USA Standard Basic Criteria for Indexes (USAS Z39.4-1968 Revision of Z39.4-1959). Sponsored by the Council on National Library Associations, the standard was prepared by Subcommittee 12 of the USA Standards Committee on
Standardization in the Field of Library Work, Documentation, and Related Publishing Practices, Z39, under the chairmanship of Jerrold Orne. Copies of the standard are available from the USA Standards Institute, 10 East 40 th Street, New York, N.Y. 10016, at $\$ 2.00$ per copy.

\section{JCL/CL SECTIONS JOINT MEETING}

At the Atlantic City Conference of the American Library Association, the Junior College Libraries Section and the College Libraries Section of the Association of College and Research Libraries will hold a joint program meeting. The topic for presentation is Library Instruction for the Undergraduate Beyond the Orientation Level, and programs of instruction at both junior college and college level will be described, with discussion following. The meeting will be on Thursday, June 26 at $4: 30$ p.m.

\section{Join the}

AMERICAN LIBRARY ASSOCIATION

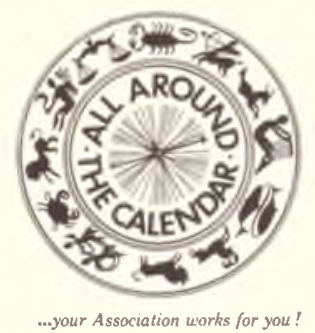

MEMEERSHIP PROMOTION AMERICAN LIORARY ASSOCIATION SO EAST HURON STREET 


\section{Why should a Science Citation Index subseriber spend $\$ 700$ a year for a PermutermSubjeet Index?}

$S C I^{\circledR}$ LINK The $P S I^{\text {TM }}$ provides the missing link to the $S C I$ if the primordial citation* is unknown or forgotten.

MULTI-ENTRY INDEXING The key to PSI

indexing is title indexing in-depth by presenting alphabetized entries for every possible pairing of words in titles and subtitles.

SPEED AND FLEXIBILITY PSI's technique of pairing words enables the user to locate any combination of terms quickly without having to $\mathrm{ex}$ amine a number of irrelevant items under a particular term.

SPECIFICITY AND SELECTIVITY PSI searches involving a single term are quick and efficient. Searches involving two or more terms are especially easy, as simple as an alphabetical look-up. Terms may even be used to exclude certain types of information.

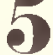

UNIQUENESS The PSI is a "natural language" indexing system based on the real language of science, the current living vocabulary used today by publishing authors, not indexers.

6 COMPREHENSIVENESS The PSI policy of indexing all articles within a journal, regardless of discipline, prevents coverage gaps associated with the selective subject indexes.

JOURNAL SELECTION The PSI selection of important journals in all important fields is based, in part, on highly accurate citation analyses of their articles, not a mindless lifting of titles from other lists.

MULTIDISCIPLINARY SCOPE The PSI covers over 90 disciplines, categorizing the journals by subject and by country.
Q EXTENSIVE COVERAGE The PSI for 1968 covers 300,000 scientific and technological items.

10

SOURCE IDENTIFICATION All the source items are listed alphabetically by author in the accompanying Source Index. The source material identifies type of items as well as all coauthors and includes full bibliographic details.

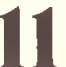

CROSS-REFERENCED AUTHORS Comprehensive cross-references are provided for every co-author. Thus, all current articles by a given author can be identified in one place in the Source Index.

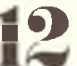

CALENDAR year COVERAGE The PSI is a calendar year index and, for the journals covered, includes all items published and available by the end of the year.

18

TRANSLATION Foreign language titles are indexed under the corresponding English terms. Judicious man-machine editing has been applied as much as possible to standardize spelling variations.

14

RELIABILITY The PSI is produced by $I S I$, leader in producing proven information retrieval and dissemination services.

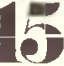

CROSS-REFERENCED SUBJECT ENTRIES Thousands of cross-references have been provided by experienced information specialists to simplify searehing and identify appropriate synonyms, spelling variants, etc.

16

MULTI-YEAR SAVINGS. If you purchase two or more years of PSI at same time you save as much as $25 \%$.

* GARFIELD, E.: Primordial concepts, citation indexing and historio-bibliography. Journal of Library History 2 (3) :235-249 (1967). Reprints available upon request, write department 12-143.

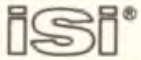

Institute for Scientific Information

325 Chestnut Street, Philadelphia, Pennsylvania 19106, U S A 